\title{
APPLICATION Of HYPERSPECTRAL THERMAL EMISSION SPECTROMETER (HYTES) DATA FOR HYSPIRI OPTIMAL BAND POSITIONING TO CHARACTERIZE SURFACE MINERALS
}

\author{
S. Ullah ${ }^{1, *}$ and A. Iqbal ${ }^{1}$ \\ ${ }^{1}$ Department of Space Science, Institute of Space Technology (IST), Islamabad- (sirifsaleem@gmail.com, \\ arshiqbal1990@gmail.com)
}

KEY WORDS: Hyperspectral, Thermal Infrared, Surface minerals, HyTES, HyspIRI, Dimensionality reduction and Genetic Algorithms

\begin{abstract}
:
This study aimed to characterize surface minerals from high dimensional HyTES (Hyperspectral Thermal Emission Spectrometer) data comprised of 256 spectral bands between 7.5 and $12 \mu \mathrm{m}$ (i.e., TIR domain of the electromagnetic spectrum). The HyTES is across-track imager and can image 512 pixels with spatial resolution varies between 5 to 50 m depending upon aircraft flying height. HyTES is developed to support the HyspIRI (Hyperspectral Infrared Imager) mission by acquiring TIR data at much higher spectral and spatial resolutions in-order to define the optimum band positions for the TIR instrument of HyspIRI. For earth compositional mapping, the HyTES images of Cuprite and Death Valley regions were acquired in summer 2014 and spectral emissivities of fifteen minerals classes were extracted from regions of known mineral compositions and were randomly divided into training and testing sets (each mineral class com-prised of 100 spectra). These extracted emissivity signatures were then used for categorizing minerals and for finding HyspIRI's optimal band positions for earth composition mapping using Genetic Algorithm (GA) coupled with Spectral angle mapper (SAM). The GA-SAM was trained for fifteen mineral classes and the algorithms were run iteratively 40 times. High calibration (>95\%) and validation (>90 \%) accuracies were achieved with limited numbers (seven) of spectral bands selected by GA-SAM. Knowing the important band Positions will help scientist of HyspIRI group to place spectral bands at regions were accuracies of Earth compositional mapping can be enhanced.
\end{abstract}

\section{INTRODUCTION}

Satellite remote sensing techniques are comprehensive means for geological analysis, especially in unapproachable areas of the earth's surface (Khan and Mahmood, 2008). For geological mapping, remote sensing is extremely effective in arid and semi-arid regions where geologic structures are widely uncovered (Khan and Mahmood, 2008). Work has been done using multispectral satellite images for mapping minerals. But due to wide band width (as the case with multispectral) is not an ideal system for mineral mapping as the absorption features are narrow and masked out with broad band width, although some people used band ratios and decorrelation stretch for mineral mapping. Hyperspectral sensors, because of their high spectral details over adjacent narrow bands, have confirmed to be a valuable tool for mapping earth composition (Ramsey et al., 2012). However, numerous spectral bands in hyperspectral sensors possess the problems of redundancy and high dimensionality. Moreover, processing hyperspectral data is computationally intensive and demanding high speed computer (Ullah et al., 2012). To overcome these afore mentioned challenges, the dimensionality of the data needs to be reduced through either band selection or band extraction. Band selection is often preferred over band extraction as the physical meaning of the data remains unaffected (Hao and Qu, 2009; Lee and Landgrebe, 1993). Genetic algorithm is a wellknown band selector and dimensionality reduction technique for spectral analysis (Ullah et al., 2012; Vaiphasa et al., 2007).
Hyperspectral VNIR-SWIR data for geology have been the attention of research and development for many years (Vaughan et al., 2003; Vaughan et al., 2005). But there are certain minerals that cannot be identified in the VNIRSWIR as there absorption features rests in TIR region of the electromagnetic spectrum. Minerals that can be readily identified in TIR include clay, carbonate, sulfate, and felsic versus mafic minerals (Crowley, 1996; Vaughan et al., 2003; Vaughan et al., 2005).

This study aims to map earth composition (minerals) using thermal infrared (TIR) data. In thermal infrared (TIR) region geology has been rarely explored and most of the fundamental absorption features for various minerals like $\mathrm{Al}-\mathrm{OH}, \mathrm{Mg}-\mathrm{OH}, \mathrm{CaCO} 3$, and sulfate minerals are situated in the TIR regions. Given this fact, the HyspIRI mission will include TIR sensor for mapping earth composition and lithology. HyspIRI thermal infrared (TIR) band positions will be based on its importance for mapping various surface minerals and this study is a precursor for finding optimal waveband positions for earth composition mapping using HyTES data. More specifically, this study aims to investigate the potential of TIR hyperspectral dataset for mineral mapping in Cuprite and Death Valley regions.

\section{METHODS AND MATERIALS}

\subsection{Study Area}

Cuprite Hills (Nevada) and Death Valley (California) are considered as study sites for the proposed research. The climate of these regions is arid in nature with barren and exposed geology making them ideal grounds for geological expeditions. Previous geological work reveals that both the 
areas are mineralogically rich, contains various important minerals such as sulfates (i.e., alunite, jarosite, kaolinite, muscovite), carbonate minerals (include calcite, dolomite and montmorillonite), iron oxides and hydroxides (i.e., hematite, goethite borates hydroboracites, pinnoite, rivadivate), evaporates minerals (i.e., anhydrite playa brines) (Clark et al., 2003; Crowley, 1993).

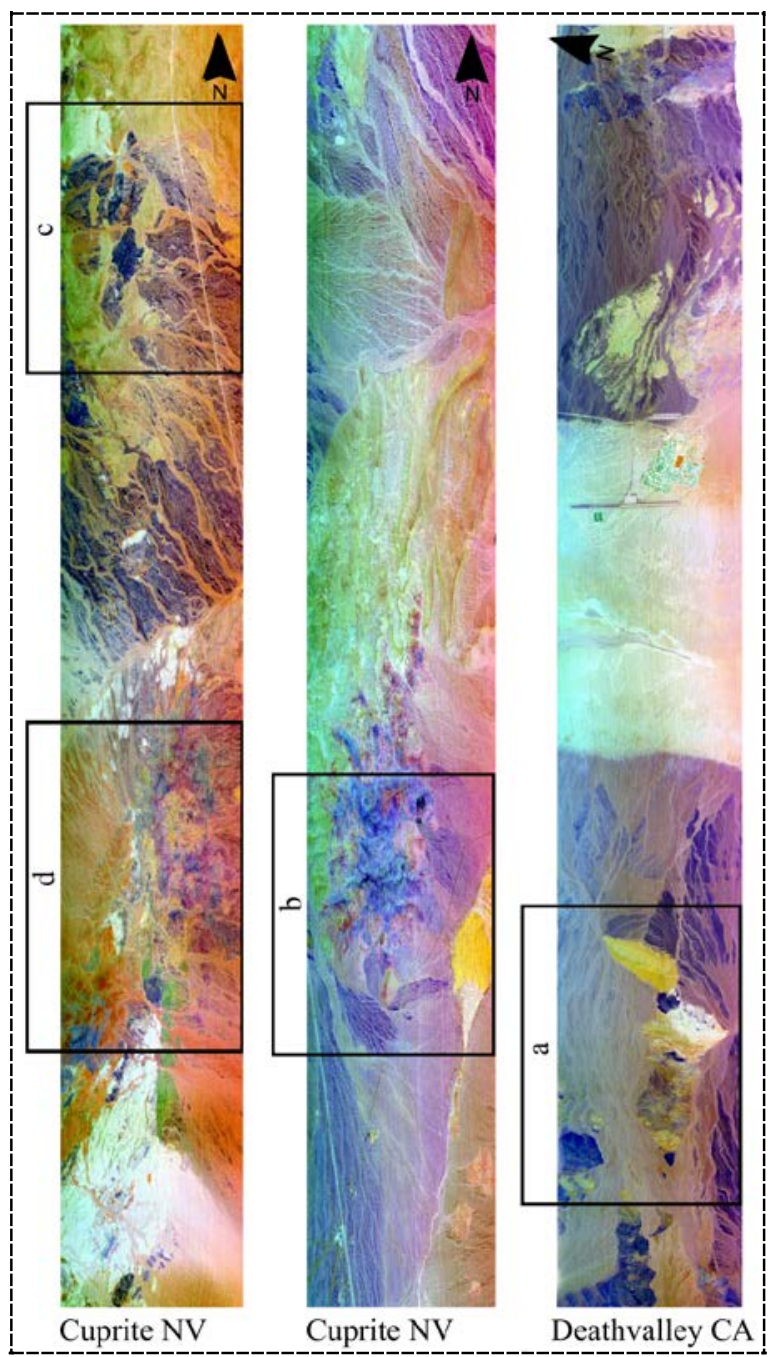

Figure 1. Study Areas

\subsection{Dataset}

The Hyperspectral Thermal Emission Spectrometer (HyTES) data (images) were used in this study. HyTES is an airborne imaging spectrometer with two hundred and fifty six (256) spectral bands placed between 7.5 and $12 \mu \mathrm{m}$ (i.e., TIR domain of the electromagnetic spectrum). HyTES is across-track imager and can image 512 pixels with spatial resolution varies between 5 to $50 \mathrm{~m}$ depending upon aircraft flying height. HyTES is developed to support the HyspIRI (Hyperspectral Infrared Imager) mission. HyTES will help the HyspIRI group to provide a data at much higher spectral and spatial resolutions in-order to define the optimum band positions for the TIR instrument of HyspIRI. The HyspIRI mission will revolve in Low Earth Orbit (LEO) and will carry two instruments onboard. The
Hyperspectral imaging spectrometer will measure from the visible to short wave infrared (VSWIR: $380 \mathrm{~nm}-2500 \mathrm{~nm}$ ) in $10 \mathrm{~nm}$ adjacent bands and a multispectral imager will acquire data from 3 to 12 um (MIR \& TIR: mid and thermal infrared) in eight spectral bands. The visible shortwave infrared (VSWIR) and thermal infrared (TIR) instruments both will have $60 \mathrm{~m}$ spatial resolution at nadir. Visible shortwave infrared will have a revisit cycle of 19 days and the thermal infrared (TIR) will have a revisit of 5 days; with swath width of 145 and $600 \mathrm{~km}$ respectively.

\subsection{Image Processing}

Genetic algorithms together with the spectral angle mapper (SAM) was used to select a meaningful subset of wavebands sensitive enough for the classification of various minerals in Cuprite Nevada and Death Valley CA (Ullah et al., 2012; Vaiphasa et al., 2007). Genetic algorithms is a popular type of evolutionary optimization computation, developed on the notion of natural selection (Fang et al., 2003; Ullah et al., 2012; Vaiphasa et al., 2007).

Spectral angle mapper (SAM) was used as an objective function for the genetic algorithms. Spectral angle mapper (SAM) nearest neighbour classifier evaluates the fitness values of the chromosome population during the process of evolution. The SAM determines the spectral match between two spectra (i.e., target and reference) by computing the angle between them in an n-dimensional space (Ullah \& Groen, 2012)

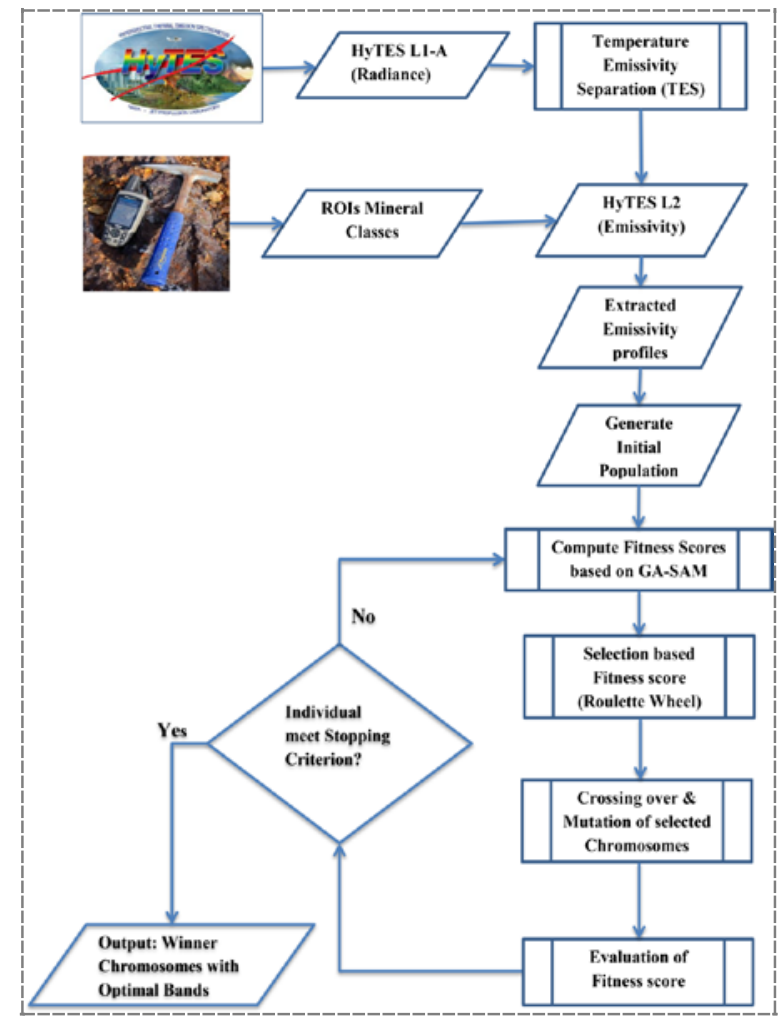

Figure 2. The methodology followed

\section{RESULTS AND DISCUSSIONS}

\subsection{Minerals Spectral profile in the TIR}


The spectral profiles of various mineral classes are distinct from each other (Figure. 3). The absorption features (associated with the different chemical compositions of a mineral) are located at different wavelength region. The variations in the absorption feature make the basis for distinguishing minerals from each other in the Image.

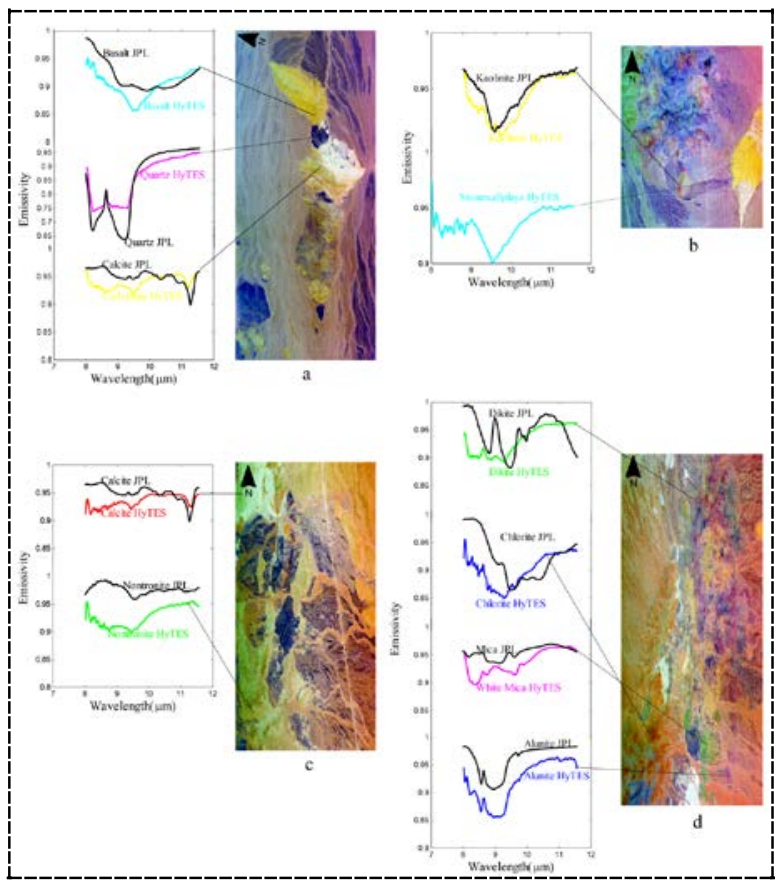

Figure 3 . The spectra profiles of various minerals

\subsection{Classification performance}

The Genetic algorithms coupled with Spectral Angle Mapper yielded a high accuracy for both the training and testing datasets (Table 1). Majority of the minerals including Quartz, Basalt, Alunite, Carbonate, Kaolinite minerals shows a perfect match with their reference spectra using meaningful subset of bands selected by genetic algorithms and SAM. The average training and testing accuracy were $97.4 \%$ and $95.87 \%$ respectively.

Table 1. Classification accuracy of SAM and Genetic algorithms using testing datasets 


\begin{tabular}{|c|c|c|c|c|c|c|c|c|c|c|c|c|c|c|c|c|c|}
\hline & 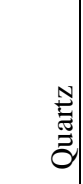 & 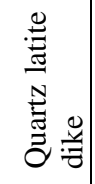 & 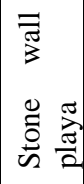 & 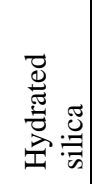 & $\begin{array}{l}\text { : } \\
0 \\
\vdots \\
0 \\
z\end{array}$ & 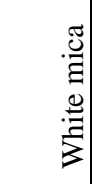 & $\begin{array}{l}\stackrel{9}{\Xi} \\
\stackrel{\Xi}{4}\end{array}$ & 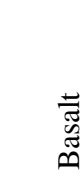 & $\frac{\mathscr{\Xi}}{\tilde{J}}$ & 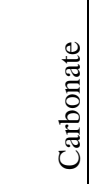 & 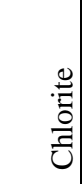 & 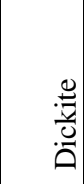 & 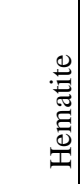 & 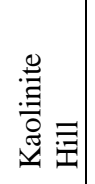 & 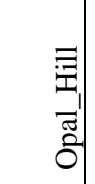 & $\begin{array}{c}\frac{n}{\pi} \\
0 \\
0\end{array}$ & 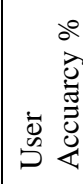 \\
\hline Quartz & 96 & 0 & 0 & 0 & 0 & 0 & 0 & 0 & 0 & 0 & 0 & 0 & 0 & 0 & 4 & 100 & 96 \\
\hline Quartz latite dike & 0 & 87 & 0 & 0 & 0 & 13 & 0 & 0 & 0 & 0 & 0 & 0 & 0 & 0 & 0 & 100 & 87 \\
\hline Stone wall playa & 0 & 0 & 100 & 0 & 0 & 0 & 0 & 0 & 0 & 0 & 0 & 0 & 0 & 0 & 0 & 100 & 100 \\
\hline Hydrated silica & 0 & 0 & 0 & 100 & 0 & 0 & 0 & 0 & 0 & 0 & 0 & 0 & 0 & 0 & 0 & 100 & 100 \\
\hline Nontronite & 0 & 0 & 0 & 0 & 100 & 0 & 0 & 0 & 0 & 0 & 0 & 0 & 0 & 0 & 0 & 100 & 100 \\
\hline White mica & 0 & 13 & 0 & 0 & 0 & 87 & 0 & 0 & 0 & 0 & 0 & 0 & 0 & 0 & 0 & 100 & 87 \\
\hline Alunite & 0 & 0 & 0 & 0 & 0 & 0 & 100 & 0 & 0 & 0 & 0 & 0 & 0 & 0 & 0 & 100 & 100 \\
\hline Basalt & 0 & 0 & 0 & 0 & 0 & 0 & 0 & 98 & 0 & 2 & 0 & 0 & 0 & 0 & 0 & 100 & 98 \\
\hline Calcite & 0 & 0 & 0 & 0 & 0 & 0 & 0 & 0 & 100 & 0 & 0 & 0 & 0 & 0 & 0 & 100 & 100 \\
\hline Carbonate & 0 & 0 & 0 & 1 & 0 & 2 & 0 & 14 & 0 & 83 & 0 & 0 & 0 & 0 & 0 & 100 & 83 \\
\hline Chlorite & 0 & 0 & 0 & 0 & 0 & 0 & 0 & 0 & 0 & 0 & 100 & 0 & 0 & 0 & 0 & 100 & 100 \\
\hline Dickite & 0 & 2 & 0 & 1 & 0 & 0 & 0 & 0 & 0 & 0 & 0 & 96 & 0 & 1 & 0 & 100 & 96 \\
\hline Hematite & 0 & 0 & 0 & 0 & 0 & 0 & 0 & 0 & 0 & 0 & 0 & 0 & 91 & 9 & 0 & 100 & 91 \\
\hline Kaolinite Hill & 0 & 0 & 0 & 0 & 0 & 0 & 0 & 0 & 0 & 0 & 0 & 0 & 0 & 100 & 0 & 100 & 100 \\
\hline Opal_Hill & 0 & 0 & 0 & 0 & 0 & 0 & 0 & 0 & 0 & 0 & 0 & 0 & 0 & 0 & 100 & 100 & 100 \\
\hline Totals & 96 & 102 & 100 & 102 & 100 & 102 & 100 & 112 & 100 & 85 & 100 & 96 & 91 & 110 & 104 & 1500 & \\
\hline Producer Accuracy\% & 100 & 85.3 & 100 & 98.0 & 100 & 85.3 & 100 & 87.5 & 100 & 97.6 & 100 & 100 & 100 & 90.9 & 96.1 & & \\
\hline
\end{tabular}




\subsection{Selected waveband positions}

Genetic algorithms coupled with Spectral Angle mapper pruned seven (7) spectral bands at each run. The algorithms were iteratively run 40 times. For 40 runs, the counts of selected bands (also called winner genes) are detailed in Figure 4 . The waveband regions with high towering were the spectral domain where winners were selected multiple times and representing the importance of these wavelengths for mineral mapping. The minute analysis of Figure 4 shows that the selected wavebands are clustering at certain waveband positions while most part of the TIR spectrum remains empty. The selected wavebands are also corresponding to the waveband position where characteristic absorption features of various minerals occure.

\section{CONCLUSIONS}

This study aims to find HyspIRI optimal TIR wavebands position for earth compositional mapping using HyTES data of Cuprite and Death Valley regions. Optimization procedure (GA-SAM) is used as spectral bands selector. The high dimensional HyTES (comprised of 256 spectral bands) data are used to select meaningful subsets of bands for earth compositional mapping. The GA-SAM yields a high calibration ( $>95 \%)$ and validation $(>90 \%)$ accuracies with limited numbers (seven) of spectral bands. This study concludes that certain wavelength regions hold high information for earth compositional mapping and are more important than others. Knowing the important band positions will help scientist of HyspIRI team (at NASA/JPL) to place spectral bands at regions were accuracies of earth compositional mapping can be enhanced.

\section{REFERENCES}

Clark, R.N., Swayze, G.A., Livo, K.E., Kokaly, R.F., Sutley, S.J., Dalton, J.B., McDougal, R.R., Gent, C.A.C., 2003. Imaging spectroscopy: Earth and planetary remote sensing with the USGS Tetracorder and expert systems. Journal of Geophysical Research: Planets 108, n/a-n/a.

Crowley, J.K., 1993. Airbone Imaging Spectrometry Mapping playa evaporite minerals with AVIRIS data: A first report from death valley, California. Remote Sensing of Environment 44, 337-356.

Crowley, J.K., 1996. Mg- and K-bearing borates and associated evaporites at Eagle Borax Spring, Death Valley, California; a spectroscopic exploration. Economic Geology 91, 622-635.

Fang, H., Liang, S., Kuusk, A., 2003. Retrieving leaf area index using a genetic algorithm with a canopy radiative transfer model. Remote sensing of environment 85, 257270.

Hao, X., Qu, J.J., 2009. Fast and highly accurate calculation of band averaged radiance. International Journal of Remote Sensing 30, 1099-1108.

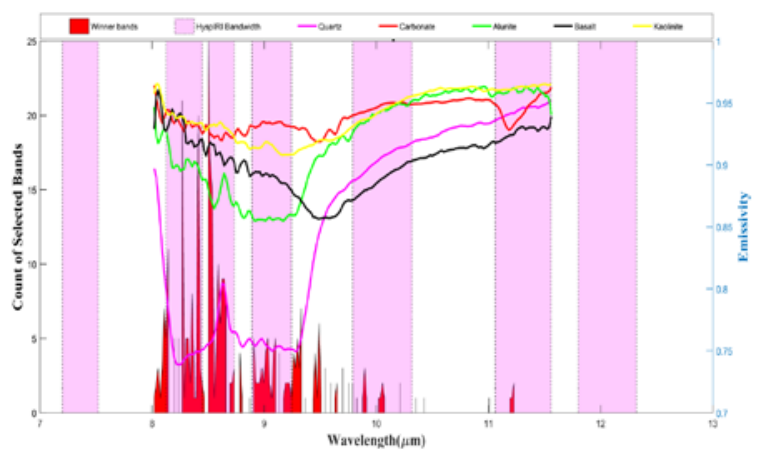

Figure 4. The count of selected (winner genes) bands after 40 runs.

Khan, S.D., Mahmood, K., 2008. The application of remote sensing techniques to the study of ophiolites. Earth-Science Reviews 89, 135-143.

Lee, C.H., Landgrebe, D.A., 1993. Feature-extraction based on decision boundaries. IEEE Trans. Pattern Anal. Mach. Intell. 15, 388-400.

Ramsey, M.S., Realmuto, V.J., Hulley, G.C., Hook, S.J., 2012. HyspIRI Thermal Infrared (TIR) Band Study Report. Jet Propulsion Laboratory (JPL) Study Report.

Ullah, S., Groen, T.A., Schlerf, M., Skidmore, A.K., Nieuwenhuis, W., Vaiphasa, C., 2012. Using a Genetic Algorithm as an Optimal Band Selector in the Mid and Thermal Infrared $(2.5-14 \mu \mathrm{m})$ to Discriminate Vegetation Species. Sensors 12, 8755-8769.

Vaiphasa, C., Skidmore, A.K., de Boer, W.F., Vaiphasa, T., 2007. A hyperspectral band selector for plant species discrimination. ISPRS Journal of Photogrammetry and Remote Sensing 62, 225-235.

Vaughan, R.G., Calvin, W.M., Taranik, J.V., 2003. SEBASS hyperspectral thermal infrared data: surface emissivity measurement and mineral mapping. Remote Sensing of Environment 85, 48-63.

Vaughan, R.G., Hook, S.J., Calvin, W.M., Taranik, J.V., 2005. Surface mineral mapping at Steamboat Springs, Nevada, USA, with multi-wavelength thermal infrared images. Remote Sensing of Environment 99, 140-158. 